\title{
Developing Innovative Support Structures in Higher Education Institutions: A Student Perspective
}

\author{
Mxolisi Walter Ntoyakhe, MS \\ Walter Sisulu University, Mthatha, South Africa \\ Musawenkosi Ngibe, $\mathrm{PhD}$ \\ Durban University of Technology, Durban, South Africa \\ (iD https://orcid.org/0000-0002-4954-1460
}

Contact: musawenkosin1@dut.ac.za

\begin{abstract}
Higher education institutions have been obliged to work extremely hard to ensure their sustainability and growth to meet the ever-increasing demands of university students, parents, and stakeholders. Universities have been under great pressure to remain competitive with a great deal of emphasis placed on being innovative, building auxiliary structures, and acquiring qualified academics. The concept of service delivery of academic departments in universities of technology has received minimal attention. This study explored student expectations and perceptions of service quality provided by academic support departments with the intention of enhancing the level of student satisfaction and experience. A quantitative research approach was employed using questionnaires. A nonprobability convenience sampling was adopted to identify 260 students. Data were coded and analyzed for descriptive analysis using SPSS Version 23.0. The findings revealed that many students were not content with various services provided by the academic departments within the university and that the academic departments did not offer students the services that they expected. The SERVQUAL dimensions displayed a negative gap in services provided by academic administrative staff. On the basis of these findings, it is recommended that the university attends to the identified key areas of concern, particularly administrative staff competency.
\end{abstract}

Keywords: middle school; content-area literacy; literacy; professional development

Date Submitted: August 2, 2018 | Date Published: May 28, 2020

\section{Recommended Citation}

Ntoyakhe, M. W., \& Ngibe, M. (2020). Developing innovative support structures in higher education institutions: A student perspective. Journal of Educational Research and Practice, 10, 104-118. https://doi.org/10.5590/JERAP.2020.10.1.07

Note: The authors would like to acknowledge the students who participated in this study and thank them for their commitment to ensuring that the study was a success. Furthermore, we would like to recognize and acknowledge the selected comprehensive university for granting permission to conduct this research. Great gratitude goes to both Walter Sisulu University and the Durban University of Technology for their academic support and financial assistance through the course of this project. 


\section{Introduction}

Many scholars have identified service quality as an innovative strategy to attract students (Abu Hasan \& Ilias, 2008; Lee, 2010; Ngibe \& Lekhanya, 2016; Sultan \& Wong, 2012). The need for higher education institutions (HEIs) to remain competitive by attempting to attract and retain high-performing students has become a major concern for universities (Koni et al., 2013; Malik et al., 2010; Mmutle \& Shonhe, 2017). Consequently, the quality of service delivered by HEIs has been acknowledged as essential for marketing and financial performance (Khan et al., 2011) and is identified as the vehicle to attract and retain fee paying students (Green \& Ramroop, 2014). Rapid changes in the economic, social, and technological spheres and demographic changes have necessitated greater demands for better quality of services offered by different institutions (Alhabeeb, 2015). Service quality determines the reputation of an organisation. To gain a competitive edge in the future, universities need to develop innovative strategies to attract students and to foster better and stronger relationships with them (Abu Hasan \& Ilias, 2008).

The importance of understanding the expectations of students as "customers" might improve the delivery of service quality within HEIs. Universities need to clearly identify students' perceptions of service quality to develop mechanisms to improve and maintain quality of services provided. Recognizing students' perceptions of the quality of the services offered and evaluating their perceptions and expectations, universities can implement mechanisms to develop quality promotion programs (Siamian et al., 2016).

Poor service delivery is prevalent in comprehensive universities in South Africa. Therefore, HEIs are obligated to review their services constantly to ensure exceptional quality services which can provide them with competitive edge (Albretch, 1991 as cited by Onditi \& Wechuli, 2017). To understand the level of satisfaction of students, the critical factors contributing to students' dissatisfaction with services provided by academic departments in the selected comprehensive university in South Africa were investigated.

\section{Aims}

The aim of this study was to investigate the effectiveness of academic support structures toward enhancing service quality provided to students at a selected comprehensive university in South Africa.

\section{Objectives}

The objectives of the study were to analyze and determine critical factors that influence students' perceptions of services offered by academic support departments and to identify innovative approaches to improve academic support structures at the selected comprehensive university.

\section{Problem Statement}

Service quality in the field of education, particularly in higher education, is not only essential but also an important factor of educational excellence (Abidin, 2015). South African HEIs, more specifically, the selected comprehensive university, have been found to been lagging behind in terms of delivering quality services to students. The critical areas of poor service quality include inadequate support from academic administrative staff, problems with student's registration, use of inexperienced staff during peak registration periods and poor academic facilities. This claim was further pointed out by van der Westhuizen (2014), who stated that poor service quality in South African universities is widely known. Consequently, the ineffective academic support structures will continue to have a negative impact on student academic performance. Conversely, an effective student service would therefore be one that assists students in their pursuit of success (Neal, 2012). Therefore, on their quest to become academic powerhouses of education and research enriched by industrial and business experience (Council of Higher Education, 2010), universities need to identify, rectify, and 
revamp their academic support structures to manage and cater for the needs of the students and most significantly enhance the standard of services provided to students.

\section{Literature Review}

\section{The Role of Academic Support Departments Toward University Students}

Education is considered as one of the basic yet pivotal needs for human development (Sivakumar \& Sarvalingam, 2010) and is pronounced as an essential component in the development and sustainable growth of the nation (Laurie et al., 2016). The need to provide efficient academic support structures to assist students in pursuing their educational goals is crucial if universities want to retain their top achieving students. Student support is one of the prerequisites of quality evaluation of HEIs and includes services such as assistance and guidance provided for student enrolment into study programmes and career aspects (Lacovidou et al., 2009; Morgan, 2012). However, to provide quality services, quality assurance is necessary (Akareem \& Hossain, 2016). Consequently, the concept and adoption of service quality has been prevalent in the higher education domain as universities are competing incessantly to acquire top achieving students (Green, 2014; Mmutle et al., 2017). Students are able to ascertain how reputable the academic support department is in supporting teaching and learning by the quality of services rendered (Tamuliené, 2013).

\section{Student Satisfaction in Higher Education}

Satisfaction is a feeling of contentment and pleasure achieved when one's needs and desires have been accomplished (Tsinidou et al., 2010; Saif, 2014). It is a construct that relates to the assessment of the perceived gap between expectations and perception of services received (Oliver, 1981, cited by Santini et al., 2017). In recent years, researchers (Butt \& Rehman, 2010; Fatima \& Fernandes, 2012; Ngibe \& Lekhanya, 2016) have paid much attention to the student satisfaction construct in an attempt to determine the general satisfaction levels of students. This highlights the influence that service quality has on the sustainability of universities nationally and abroad. The gap between the students' expectation of the quality of service and the perceived quality of the service received can be explained by the gaps model (Green, 2014) and SERVQUAL, a service quality scale (Chou et al., 2011).

Both the students and their parents are looking for added value for their money (Sharabi, 2010), and HEIs have to deliver quality that is compatible with students' expectations and needs (Smith et al., 2007). Therefore, it is important for universities to fully identify with their mission and the needs and expectations of the students they serve (Manuel, 2008).

\section{Measuring Tools: Gaps Model and the SERVQUAL Model}

The measuring tools propose the significant extent in identifying the gaps that exist between the expected and perceived services. The gaps model of service quality was first developed by Parasuraman and colleagues (1988) and was popularly used as a framework for research in servicing marketing departments for over 2 decades (Onditi \& Wechuli, 2017). This model measures and shows consistancy or inconsistencies of perceived and experienced services by customers. The purpose for this is to indentify whether there are any service quality gap in the services provided by university. Once service quality gaps have been identified, the university can be able to identify remedial approaches to improve services provided to students. As indicated by Dehghan and Shahin (2011), customer satisfaction can be secured when the actual performance meets or surpasses the expectation of those being served. However, Foster (2010) argued that the developemnt of SERVUAL by Parasuraman et al. has been integrated slowly and is gaining momentum in higher education due to constant changes in social economy, demographics, and student preferences. 
Foster (2010) further stated that SERVQUAL identifies five discrepancies, or "gaps," that may cause problems in service delivery and therefore influence customer evaluations of service quality: (a) between customer expectations and management's perception of these expectations, (b) between management's perception of what customers (students) want and the specifications that management develops to provide the service, (c) between the service quality specifications (delivery systems) and the service that is actually provided, (d) between what the service system actually provided and what the customer is told it provides (a communication gap), and (e) between customers' perceptions of service performance and their expectations.

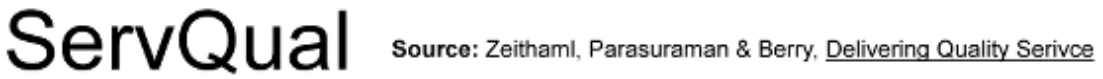

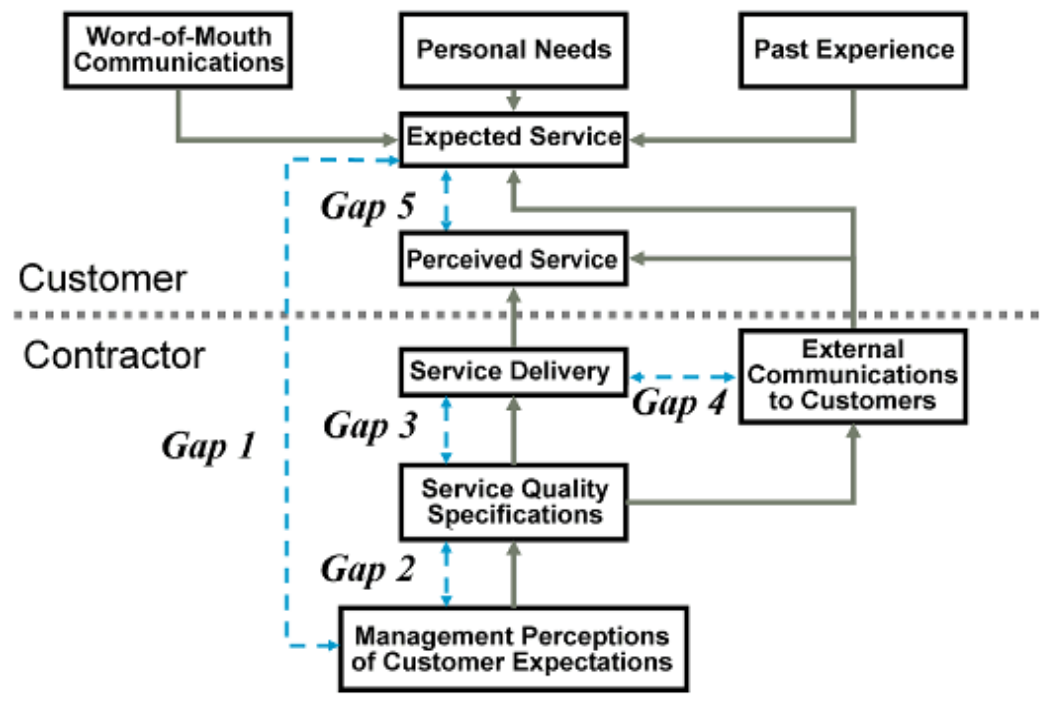

\section{Figure 1. SERVQUAL Model}

Parasuraman and colleagues (1988) originally proposed 10 dimensions of service quality: Tangibility, Reliability, Responsiveness, Competence, Courtesy, Credibility, Security, Access, Communication, and Understanding the Customer. Their research was later refined, leading to the development of the SERVQUAL scale, which measures customers' perceptions of service quality. The original 10 dimensions were compacted into five: Reliability, Responsiveness, Assurance, Empathy, and Tangibles.

\section{Reliability}

Yeo (2008) stated that the discrepancy between the service promise and service delivery is often mainly due to inaccurate communication from advertisements and exhibitions.

\section{Responsiveness}

According to Govender and colleagues (2014), responsiveness refers to the promptness and willingness to serve the staff demonstrates during the service encounter. This dimension focuses on attentiveness and promptness in dealing with customers' requests, queries, complaints, and problems. 


\section{Assurance}

Assurance relates to the ability of the staff to provide a courteous and secure service. As stated by Arasli et al. (2005), assurance includes employees' knowledge, courtesy, and the ability to instill trust and confidence in the customers.

\section{Empathy}

The focal point of empathy is the message that customers are unique and special. Curry \& Sinclair (2002) viewed empathy as providing caring, personalized attention to the customers.

\section{Tangibles}

According to van de Westhuizen (2014), tangibles are viewed as facilities, equipment, and the personal appearance of staff at the institution. Tangibles provide physical representations that students will use to evaluate service quality.

\section{Research Methodology}

A quantitative, descriptive research approach was adopted for this study. Descriptive research attempts to describe characteristics of a sample and relationships between phenomena, situations, and events observed by the researcher (Offredy \& Vickers, 2010; Thyer, 2010). The use of this approach enabled the researcher to identify and examine the factors contributing to students' dissatisfaction toward the services provided by academic support staff.

\section{Study Sample Size}

The target population for this study consisted of 260 full-time registered students with adequate knowledge pertaining to the services provided by the academic support department within the university. A nonprobability convenience sampling technique was used to target individuals whose experience would be of value to the study. Subsequently, a convenience sampling technique was employed based on its flexibility to allow the researcher to focus on how relevant the sample is rather than on how representative it is (Offredy \& Vickers, 2010).

\section{Data Collection Method}

A carefully designed, closed-ended questionnaire was used. Using a 5-point Likert scale format, the questionnaire captured the levels of expectations and perceptions of the respondents toward the services provided by the academic support departments. Questionnaires were randomly disseminated to 260 students. A 100\% response rate was achieved.

The development of the questionnaire was designed strictly in line with the SERVQUAL instrument developed by Parasuraman et al. (1988). The questionnaire tested the dimensions of Reliability, Responsiveness, Assurance, Empathy, and Tangibles. The adoption of the instrument helped to identify and highlight gaps in the services provided by academic support departments.

\section{Data Analysis}

Prior to the analysis of data, a thorough cross-check and data cleaning were conducted to ensure that the data were error free. A descriptive analysis was performed using SPSS Version 23.o. Frequencies were used to determine the number of responses that each question received to make meaningful comparisons. The information gathered from the frequencies allowed for a comparison between key variables. Descriptive analysis will be presented. 


\section{Validity and Reliability}

The questionnaire was reviewed by research experts in the field, a statistician, and a professional editor prior to distribution for data collection. The reliability test was conducted using Cronbach's alpha, resulting in a coefficient of 0.70 . The results indicate that the reliability scores of the study were acceptable. Table 1 depicts the reliability scores for each dimension of the SERVQUAL instrument.

Table 1. Academic Support Structure Reliability Scores for Each Dimension of the SERVQUAL Instrument

\begin{tabular}{lcccc}
\hline \multirow{2}{*}{$\begin{array}{c}\text { SERVQUAL } \\
\text { dimension }\end{array}$} & \multicolumn{2}{c}{ Expectations } & \multicolumn{2}{c}{ Perceptions } \\
\cline { 2 - 5 } & Items, $\boldsymbol{N}$ & Cronbach's $\boldsymbol{\alpha}$ & Items, $\boldsymbol{N}$ & Cronbach's $\boldsymbol{\alpha}$ \\
\hline Reliability & 6 & 0.831 & 6 & 0.755 \\
Responsiveness & 4 & 0.862 & 4 & 0.761 \\
Assurance & 8 & 0.927 & 8 & 0.878 \\
Empathy & 6 & 0.912 & 6 & 0.816 \\
Tangibles & 7 & 0.913 & 7 & 0.807 \\
\hline
\end{tabular}

\section{Results}

The scoring patterns of the respondents per variable per section are presented here. The gaps identified result from the discrepancy between the measure of students' expectations and their perception of the services received.

\section{Reliability}

Reliability was scored as the ability of the academic administrators to perform the promised services independently and accurately (Figure 2). The overall gap score of -1.8 is similar to the individual gaps for each statement. A gap score of approximately -2 is considered significant. The expectation scores are high ( $\geq 4.2$ ) and correspond to strong levels of agreement with each of the statements. The perceptions score (2.3) averages between the levels of agreement are neutral. The statement whether the institution provides services within the expected time (Statement B1Rel1) resulted in the highest gap score of -2.0. The statements as to whether academic administrators solved problems and dealt with complaints with concern and sympathy (Statement B1Rel4), behaved in a manner that gave the students trust and confidence in them (Statement B1Rel5), and provided a service that was dependable and reliable (Statement B1Rel6) resulted in the next highest gap scores of $\mathbf{- 1 . 9}$. The statement as to whether academic administrators have the requisite knowledge to answer questions relating to courses offered (Statement B1Rel2) resulted in a gap score of -1.8 . The lowest gap was -1.6 , given in response to the statement concerning accurate and retrievable records being kept by administrative staff (Statement B1Rel3). This means that the students were not entirely satisfied with the information given to them by administrators in any of the services tested by the model.

It is common knowledge that clients normally expect services to be carried out reliably, accurately, and effectively and within a good turnaround time (Reddy, 2014). Rosa and colleagues (2012) emphasized that when a student requests a service, the institution or department should adequately fulfill that request. As concluded by Pathmini (2016) in a study on the impact of service reliability on student satisfaction conducted in Sri Lanka, service reliability is significant to student satisfaction. This dimension shows that the ability of 
the academic administrators to perform their service dependably and accurately needed improvement across all measured segments.

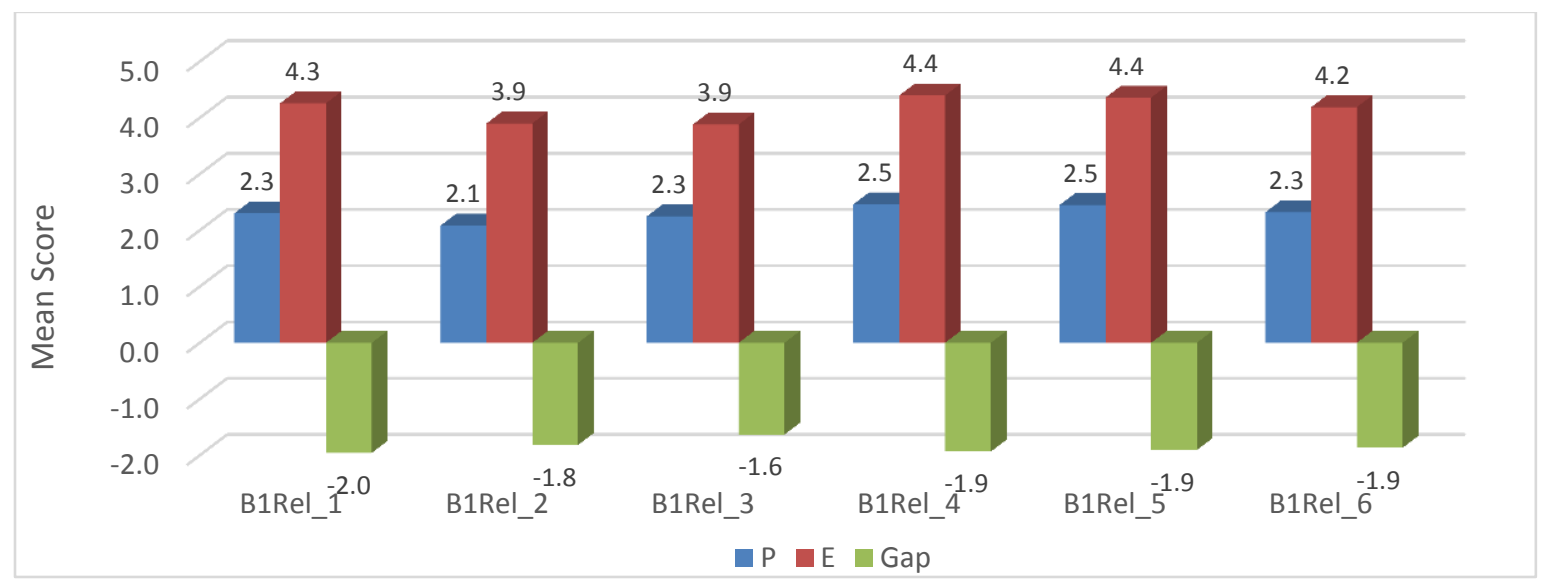

Figure 2. Reliability Dimension Score. $P=$ perceptions; $E=$ expectations.

\section{Responsiveness}

Responsiveness was indicated by the willingness of academic administrators to help students and provide a prompt service (Figure 3). The overall gap score of -1.8 is similar to the individual gaps for each statement. The expectation scores are high $(\geq 4.1)$ and correspond to strong levels of agreement with each of the statements. The perceptions score (2.3) average between the levels of agreement and neutral. This indicates that the respondents perceived that the services provided by the academic administrators were somewhat lacking.

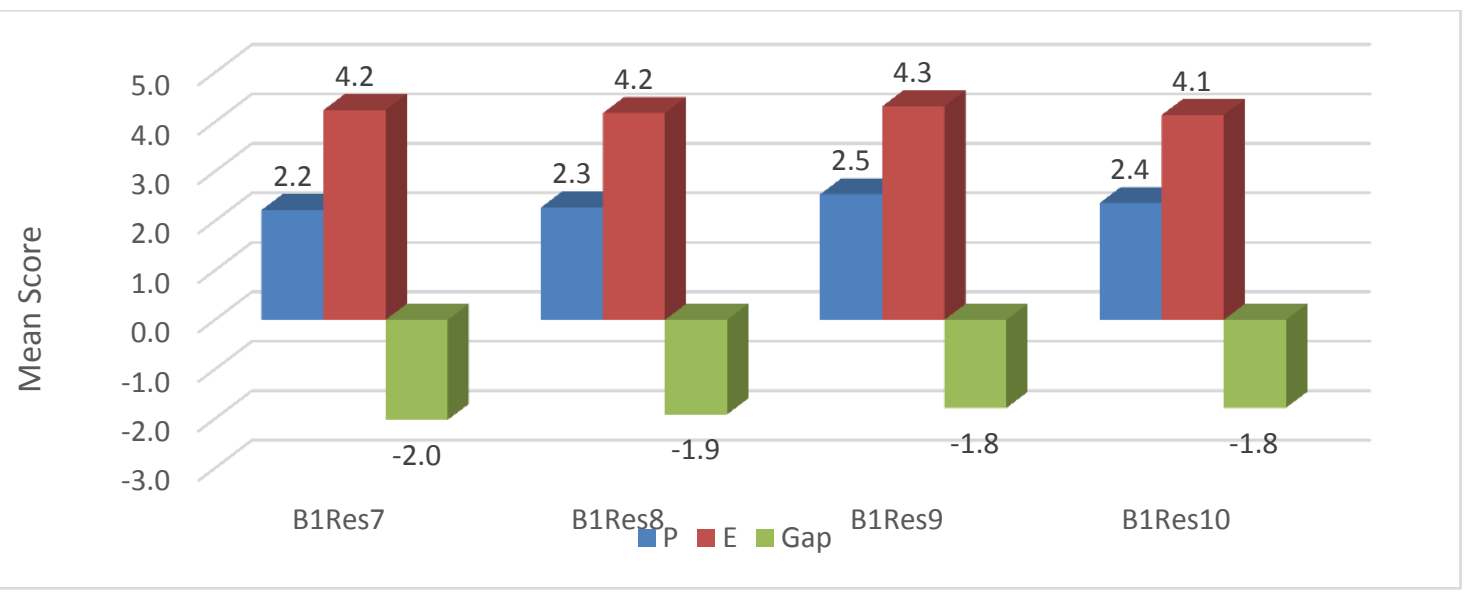

Figure 3. Responsiveness Dimension Score. $P$ = perceptions; $E$ = expectations.

The highest gap is $\mathbf{- 2 . 0}$ based on whether academic administrators deal with queries within the university efficiently and promptly (Statement B1Res7). The statement whether administrative staff show willingness to 
assist students (Statement B1Res8) resulted in a gap score of -1.9. The statements whether administrative staff were never too busy to respond to a request for assistance (Statement B1Res9), and whether they can be contacted easily by telephone (Statement B1Res10) resulted in similar gap scores of -1.8 indicating the lowest gap scores in this dimension. Academic administrators are perceived as not willing to assist students as expected and that the students are also not fully informed about the types services rendered. As highlighted earlier, the promptness and efficiency of academic administrators in dealing with students' queries within the institution, has recorded the highest gap score of -2 .

\section{Assurance}

Assurance was measured by the knowledge and courtesy of the academic administrators and their ability to convey trust and confidence (Figure 4). The perceptions score (2.3) average between the levels of agreement and neutral. The largest gap score of -1.8 referred to statements whether academic administrators make students feel entirely safe in dealing with their transactions (Statement B1Ass13), are friendly and polite (Statement B1Ass14), have adequate staff members to carry out the duties and services they provide (Statement B1Ass16), and are always willing to help students (Statement B1Ass18). Statements on whether academic administrators deal with queries within the institution efficiently and promptly (Statement B1Ass11), respect confidentiality when information is disclosed to them (Statement B1Ass12) and have the knowledge needed to answer customer enquiries (Statement B1Ass15) had a gap score of -1.7. The lowest gap score is -1.6 , based on the statement whether academic administrators provide helpful answers which are easy to understand when handling student queries (Statement B1Ass17). Therefore, respondents were not entirely happy with the way the academic administrators communicated, meaning that the information communicated to them was sometimes inaccurate and not always easy to understand. Noe (2010) stated that, in building trust and good collaborative working relationships, it is essential to have good communication skills and the ability to convey clear and precise information to students. The students did not feel completely secure nor did they entirely trust academic administrators in terms of information protection during the problem-solving process. The findings suggest that there is certainly a gap in terms of trust that needs be addressed to enable academic administrators to follow all the necessary steps to protect students' information. It is important to gain students' trust as emphasized by Montoya and colleagues (2010), who believed that trust is at the core of the relationship.

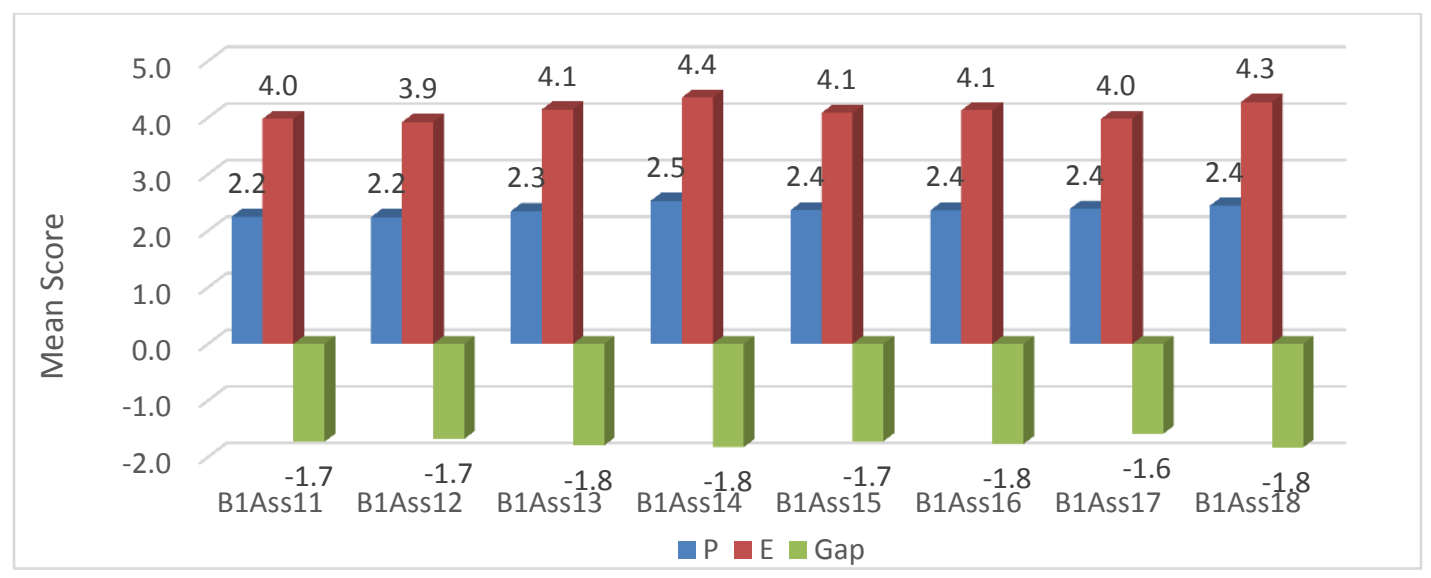

Figure 4. Assurance Dimension Score. $P=$ perceptions; $E=$ expectations. 


\section{Empathy}

Empathy scores considered the individualized attention provided to students by academic administrators (Figure 5). The average expectation is 4.2 while the average perception is 2.4 . The responses to the statements that the academic administrators always give students individual attention (Statement B1Emp19), and whether the safety of students is guaranteed (Statement B1Emp24) resulted in a high gap score of -1.9. The average gap score of -1.8 referred to statements whether students perceived that the academic administrators show a sincere interest in solving their problem (Statement B1Emp20), appear to have best interest at heart (Statement B1Emp22), and understand the specific needs of students (Statement B1Emp23). The smallest gap score of -1.7 pertained to the students perceiving the academic administrators to have convenient operation hours (Statement B1Emp21). With regard to this statement, the selected university conforms to the operational hours set by the university council and the Department of Higher Education as it is a public university. The greatest concern is in understanding and meeting students' needs.

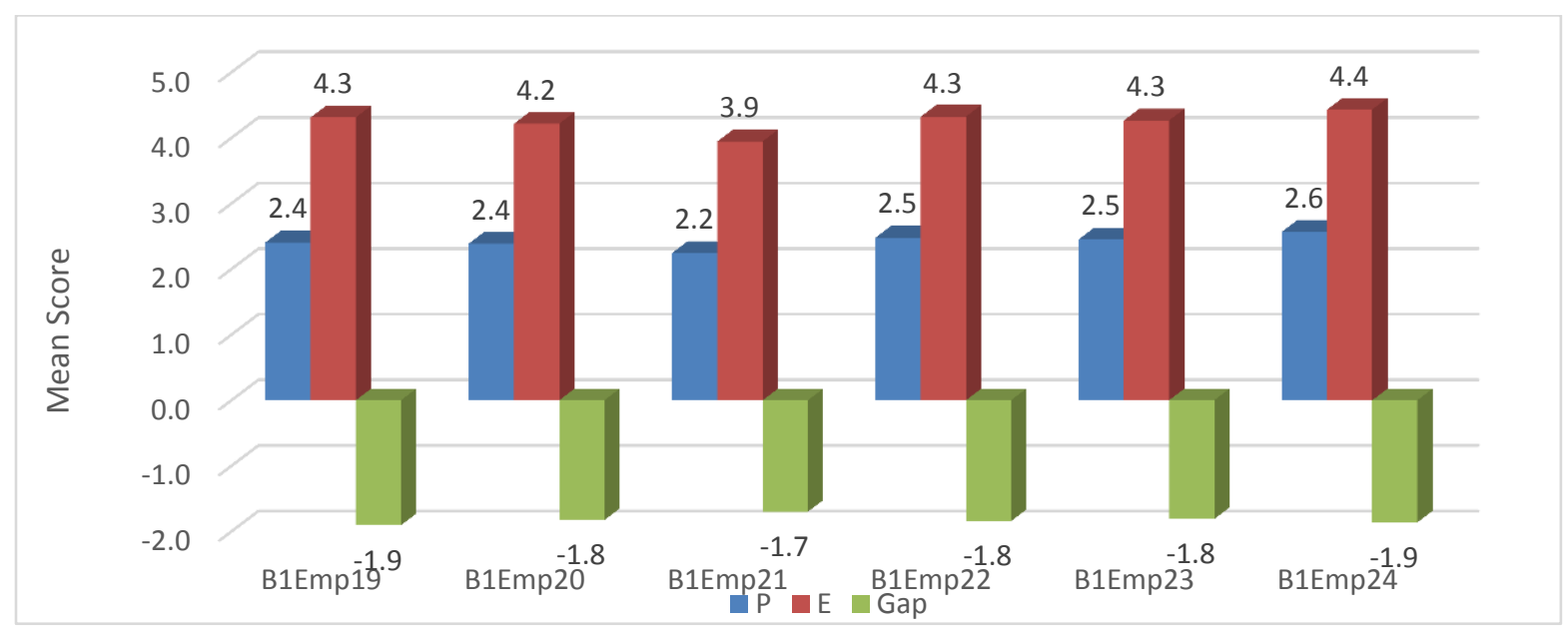

Figure 5. Empathy Dimension Score. $P$ = perceptions; $E=$ expectations.

\section{Tangibles}

Tangibles refer to facilities, equipment, and personal appearance of the academic administrators at the institution (Figure 6). The average expectation is 4.2 and the average perception is 2.4. The response to whether the academic administrators had sufficient computers, printers, and copiers, and so on required to do their work (Statement B1Tan25); adequate administrative personnel to assist students (Statement B1Tan26); up-to-date technical equipment (Statement B1Tan27); and appropriate tools and instruments to provide service (Statement B1Tan29) and whether the appearance of offices was attractive (Statement B1Tan30) resulted in a gap score of -1.8 , which is the highest gap score for this dimension. Statement B1Tan28, which refers to whether physical facilities are visually appealing, resulted in an average gap score of -1.7 . The lowest gap was -1.6 , based on the statements asking whether power cuts, due to poor maintenance of university power facilities, seldom occur. 


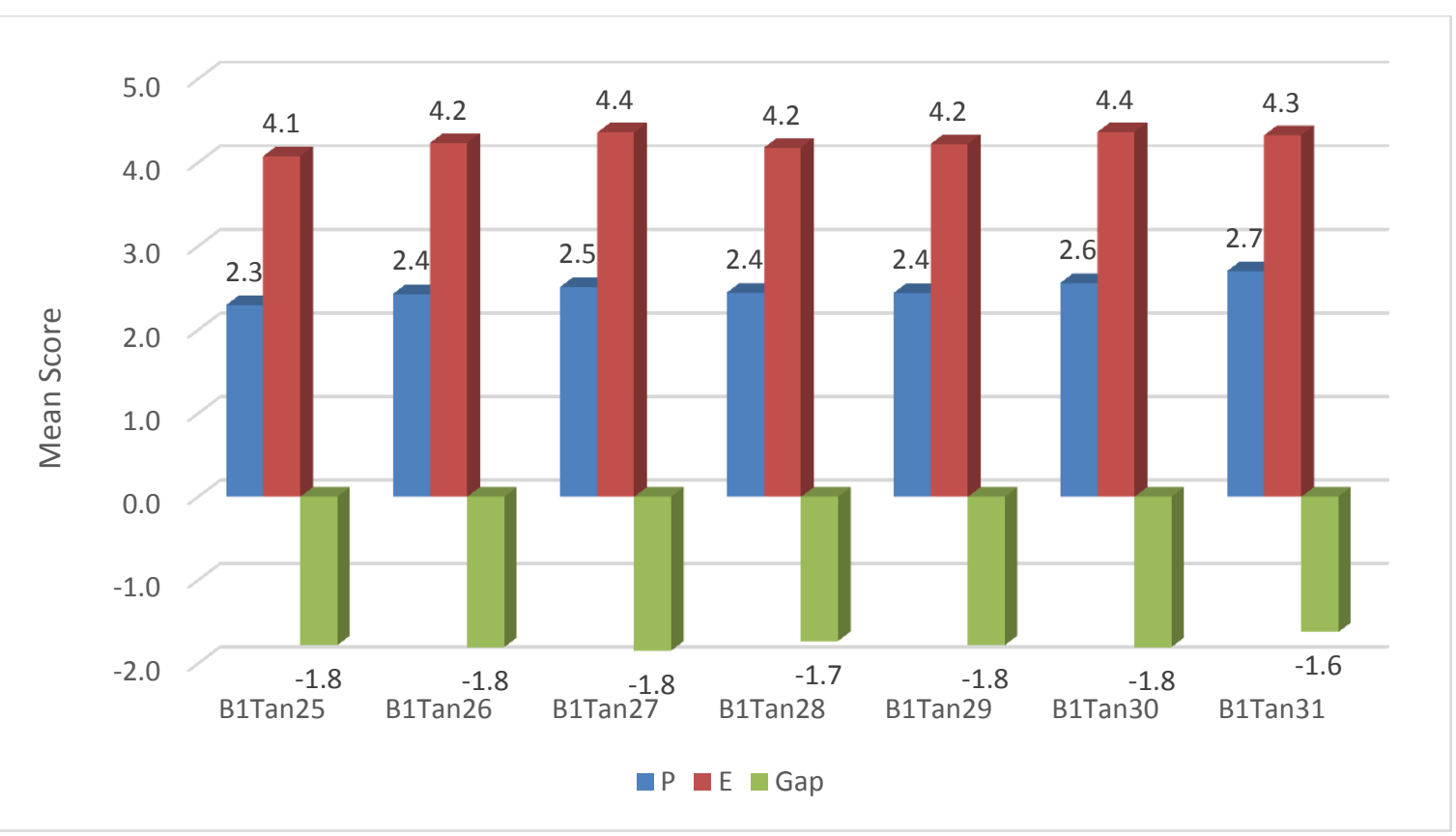

Figure 6. Tangibles Dimension Score. $P=$ perceptions; $E=$ expectations.

The responses indicated that the academic administrators need to promote their services effectively by being neat and smart in appearance, provide up-to-date technology to deliver the service efficiently and provide service professionally. This is emphasized by Zhao and Benedetto (2013), who stated that although service quality measures customer satisfaction against a service delivered, students' expectations must be met in terms of designing materials and facilities appropriately and training academic administrators adequately. Academic administration was negatively perceived in terms of attraction and the visual appeal of the physical facilities and the fact that the institution does not have signage locating the departments and structures.

\section{Discussion}

\section{Recommendations}

The results of this study indicated that the students were not satisfied with the services provided by academic support structures across all five tested dimensions. The highest performance gap in the dimensions was assurance followed respectively by tangibles, reliability, empathy, and responsiveness. The following recommendations have been made to improve the quality of services provided by academic support departments.

\section{Assurance}

The imperative way to improve assurance of the services provided by academic administrative departments is to improve their administrator's level of skills and capabilities and also understanding their roles, responsibilities, and, most importantly, the academic administrative processes. The development of administrative staff capabilities should not only focus on the job they are performing but also on managing diverse students, academics, stakeholders, and the public. Therefore, it would be beneficial to organize inhouse workshops specifically on academic administrative processes to improve their level of understanding, 
which will in turn instill confidence among students that the administrators have the ability to convey trustworthy and dependable information.

\section{Tangibles}

Based on the findings, it has been determined that a lack of proper resources and facilities, outdated equipment, and a shortage of staff members were factors that played a critical role in supporting the delivery of services to students. Without these requirements, academic administrative offices are likely to be inactive, resulting in poor administrative assistance. It is further recommended that the selected university invest in employing qualified administrators. An initiative should also be made by the university to orientate, mentor, and train these administrators so that they fully understand the vision of the institution and their role and influence toward this vision. Therefore, it is important that the departments attend to these critical issues with urgency to minimize this gap.

\section{Reliability}

Based on finding of this study, students were not entirely satisfied with the level of competency shown by academic administrative staff. Their ability to handle student's queries and prompt attendance to enquiries were recorded as the highest gap. As recommended earlier, this issue can be minimized if the university could employ additional academic administrators to alleviate the pressure that is felt by the few employees that are responsible for the large number of students enrolled at the university. Considering the expectations and preferences of the students, the university needs to align the academic support services to the needs of the students, to support their academic activities and instil confidence in students, and to enhance reliability of the academic support departments.

\section{Empathy}

Due to a lack of personnel and the large number of registered students, it is evident that time and workload did not permit academic administrators to provide individualized attention to students. The need to have meetings with students on a monthly or termly basis is indicated here as this could alleviate the sense of not belonging and improve student engagement with the department.

\section{Responsiveness}

In order for academic administrators to improve their level of responsiveness to student enquiries, they need to have a better understanding of the services they are providing. They also need to have an automated filling system that will be able to efficiently and promptly retrieve students' records. Each department should have at least two administrators to improve the effectiveness and continuation of work in case one of the administrators falls ill or has family responsibilities. Furthermore, it is recommended that, academic support departments should have a 24 -hr helpline or website that assists with general questions which do not need face-to-face consultation.

Considering the high level of competition amongst universities, nationally and internationally (Azoury et al., 2013), it is imperative that the selected university prioritizes service quality (Alhabeeb, 2015; Cardona \& Bravo, 2012) as a strategic approach to establishing itself as the preferred university for developing leadership in technology and promoting excellence in learning and teaching.

\section{Conclusions}

The conclusions are based on the findings and the aim and objectives of this study. The aim of this study was to investigate the effectiveness of academic support structures toward enhancing service quality provided to students at a selected comprehensive university in South Africa. The results revealed that the requirement of strategic approaches to strengthen and improve service quality depended on the university's ability to review the services provided as all five dimensions tested (academic support structures' reliability, responsiveness, 
empathy, assurance, and tangibles) reflected a negative gap score. Therefore, it is concluded that the level of student satisfaction is correlated with the ability of the academic administrators to deliver the promised services independently and accurately-that is, the ability of academic administrators to help students willingly by providing prompt services, having the knowledge and courtesy, and having advanced facilities and equipment to assist in providing quality services. The study further concludes that the recruitment of additional qualified administrative personnel will drastically improve the level of support and services provide to students. Therefore, it is imperative that the selected comprehensive university develops the skills of the administrative staff, improves the level of services rendered to students by actually aligning the services to the needs of the students, establishes mechanisms to evaluate student satisfaction (every semester), and invests in facilities that are conducive for administrative staff to perform their duties and manage student demands.

\section{References}

Abidin, M. (2015). Higher education quality: Perception differences among internal and external stakeholders. International Education Studies, 8(12), 185-192.

Abu Hasan, H. F. A., \& Ilias, A. (2008). Service quality and student satisfaction: A case study at private higher education institutions. International Business Research, 1, 163-175.

Akareem, H. S., \& Hossain, S. S. (2016). Determinants of education quality: What makes students' perception different? Open Review of Educational Research, 3(1), 52-67.

Alhabeeb, A. M. (2015). The quality assessment of the services offered to the students of the college of education at King Saud University using SERVQUAL method. Journal of Education and Practice, 6(30), 82-93.

Arasli, H. A., Mehtap, S., \& Katircioglu, S. T. (2005). Customer service quality in the Greek Cypriot banking industry. Journal of Managing Service Quality, 15(1), 41-56.

Azoury, N. M., Daou, L. E., \& Khoury, C. M. (2013). University Image and its relationship to student satisfaction: Case of the Holy Spirit University of Kaslik, Lebanon. Journal of Executive Education, 12(1), 1-13.

Butt, B. Z., \& Rehman, R. U. (2010). A study examining the students' satisfaction in higher education. Procedia Social and Behavioral Sciences, 2, 5446-5450.

Cardona, M. M., \& Bravo, Y. J. (2012). Service quality perceptions in higher education institutions: The case of a Colombian university. Estudios Gerenciales Journal, 28, 23-29.

Chou, C. C., Liu, L. J., Huang, S. F., Yih, J. M., \& Han, T. C. (2011). An evaluation of airline service quality using the fuzzy weighted SERVQUAL method. Applied Soft Computing, 11, 2117-2128.

Council of Higher Education. (2010). Comprehensive universities: Deepening the debate. http://www.che.ac.za/sites/default/files/publications/Kagisano_No 7 February2010.pdf

Curry, A., \& Sinclair, E. (2002). Assessing the quality of physiotherapy services using SERVQUAL. International Journal of Health Care Quality Assurance, 15(5), 197-205.

Dehghan, A., \& Shahin, A. (2011). Service quality gaps and six sigma. Journal of Management Research, 4(6), 1-12

Fatima, S., \& Fernandes, P. O. (2012). Empirical study on the student satisfaction in higher education: Importance-satisfaction analysis. International Journal of Educational and Pedagogical Sciences, 6(6), 1609-1614.

Foster, S. T. (2010). Managing quality: Integrating the supply chain (4th ed.) Prentice-Hall. 
Govender, J. P., Veerasamy, D., \& Noel, D. T. (2014). The service quality experience of international students: The case of a selected higher education institution in South Africa. Mediterranean Journal of Social Sciences, 5(8), 465-473.

Green, P. (2014). Measuring service quality in higher education: A South African case study. Journal of International Education Research, 10(2), 132.

Green, P., \& Ramroop, S. (2014). Service delivery at a satellite campus: A Durban University of Technology case study. International Journal of Education Science, 7(3), 615-622.

Khan, M. M., Ahmed, I., \& Nawaz, M. M. (2011). Student's perspective of service quality in higher learning institutions: An evidence-based approach. International Journal of Business and Social Science, 2(11), 159-164.

Koni, A., Zainal, K., \& Ibrahim, M. (2013). An Assessment of the services quality of Palestine higher education. International Education Studies, 6(2), 33-48.

Lacovidou, M., Gibbs, P., \& Zopiatis, A. (2009). An Exploratory use of the stakeholder approach to defining and measuring quality: The case of a Cypriot higher education institution. Quality in Higher Education, 15(2), 147-165.

Laurie, R., Nonoyama-Tarumi, Y., Mckeown, R., \& Hopkins, C. (2016). Contributions of education for sustainability development (ESD) to quality education: A synthesis of research. Journal of Education for Sustainable Development, 10(2), 226-242.

Lee, J. (2010). Online support service quality, online learning acceptance and student satisfaction. Internet and Higher Education, 13, 277-283.

Malik, M. E., Danish, R. Q., \& Usman, A. (2010). The Impact of service quality on students' satisfaction in higher education institutes. Journal of Management Research, 2(2), 2.

Manuel, N. (2008). Customer perception of service quality at the Business Studies Unit of the Durban University of Technology (Unpublished Master's thesis). Durban University of Technology.

Mmutle, T., \& Shonhe, L. (2017). Customers' perception of service quality and its impact on reputation in the hospitality industry. African Journal of Hospitality, Tourism and Leisure, 6(3), 1-25.

Montoya, M. M., Massey, A. P., \& Khatri, V. (2010). Connecting IT services operations to services marketing practices. Journal of Management Information Systems, 26(4), 65-85.

Morgan, M. (2012). The evolution of student services in the U.K. Perspectives: Policy and Practice in Higher Education, 1, 1-8.

Neal, P. (2012). Student perceptions of the value of student services at a for profit 2-year college (Master's thesis). University of Akron.

Ngibe, M., \& Lekhanya, L. M. (2016). Perceptions of research structures and service quality within various faculties at Durban University of Technology: Staff and students' perspective. Problems and Perspectives in Management, 14(1), 192-200.

Noe, D. P. (2010). Why good communication skills are important in the workplace. http://careerpath360.com/index.php/why-good-communication-skills-are-important-in-theworkplace-8524.

Offredy, M., \& Vickers, P. (2010). Developing a healthcare research proposal: An interactive student guide. Wiley-Blackwell. 
Onditi, E. O., \& Wechuli, T. W. (2017). Service quality and student satisfaction in higher education institutions: A review of literature. International Journal of Scientific and Research Publications, $7(7), 328-335$.

Parasuraman, A., Zeihaml, V., \& Berry, L. L. (1988). SERVQUAL: A multi-item scale for measuring consumer perception of the service quality. Journal of Retailing, 64(1), 12-40.

Pathmini, M. G. S. (2016). Impact of service reliability on student satisfaction in newly established public sector universities (NEPUs) in Sri Lanka: Perspective on undergraduates in management faculties. International Journal on Global Business Management and Research, 5(1), 11-20.

Reddy, N. (2014). Perceptions and expectations of information technology service delivery post migration to a Microsoft platform at a university of technology in South Africa (Master's thesis). Durban University of Technology.

Rosa, M. D. M., Gama, N., \& Silva, M. M. D. (2012). A method for identifying IT services using incidents. Proceedings of the Eighth International Conference on the Quality of Information and Communications Technology, IEEE, Lisbon, Portugal.

Saif, N. I. (2014). The effect of service quality on student satisfaction: A field study for health service administration students. International Journal of Humanities and Social Science, 4(8), 172-181.

Santini, F. O., Ladeira, W. J., Sampaio, C. H., \& Costa, G. S. (2017). Student satisfaction in higher education: Meta-analytic study. Journal of Marketing for Higher Education, 27(1), 1-18.

Sharabi, M. (2010). HR manager leadership in quality improvement in a college environment. Quality Assurance in Education, 18(4), 317-327.

Siamian, H., Rostami, F., Gara, A. N., \& Abedi, G. (2016). The students' viewpoint on quality of educational services in Iran. https://www.ncbi.nlm.nih.gov/pmc/articles/PMC5402359/pdf/MSM-29-48.pdf

Sivakumar, M., \& Sarvalingam, A. (2010). Human deprivation index: A measure of multidimensional poverty. https://mpra.ub.uni-muenchen.de/22337/1/MPRA paper 22337.pdf

Smith, G., Smith, A., \& Clarke, A. (2007). Evaluating service quality in universities: A service department perspective. Quality Assurance in Education, 15(3), 334-353

Sultan, P., \& Wong, H. Y. (2012). Service quality in a higher education context: An integrated model. Asia Pacific Journal of Marketing and Logistics, 24(5), 755-784.

Tamuliené, R. (2013). Adjusting college students' support services to students' type: Lituania's case. Procedia - Social Behavioral Sciences, 141, 438-446.

Tsinidou, M., Gerogiannis, V., \& Fitsilis, P. (2010). Evaluation of the factors that determine quality in higher education: An empirical study. Quality Assurance in Education, 18(3), 227-244.

Thyer, B. (2010). The handbook of social work research methods (2nd ed.). Sage.

van der Westhuizen, E. J. (2014). Student experiences of service delivery in an academic department at a higher education institution in South Africa. Journal of Public Administration, 49(1), 406-423.

Yeo, R. K. (2008). Brewing service quality in higher education. Quality Assurance in Education Journal, 16(3), 270-271.

Zhao, Y. L., \& Benedetto, A. D. (2013). Designing service quality to survive: Empirical evidence from Chinese new ventures. Journal of Business Research, 66(8), 1098-1107. 
Ntoyakhe \& Ngibe, 2020

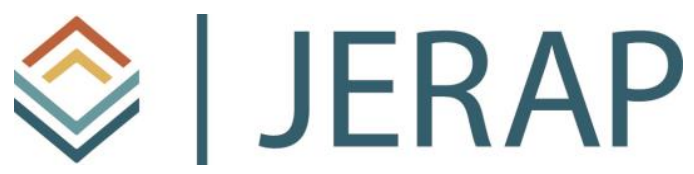

The Journal of Educational Research and Practice is a peerreviewed journal that provides a forum for studies and dialogue about developments and change in the field of education and learning. The journal includes research and related content that examine current relevant educational issues and processes. The aim is to provide readers with knowledge and with strategies to use that knowledge in educational or learning environments. JERAP focuses on education at all levels and in any setting, and includes peer-reviewed research reports, commentaries, book reviews, interviews of prominent individuals, and reports about educational practice. The journal is sponsored by the Richard W. Riley College of Education and Leadership at Walden University, and publication in JERAP is always free to authors and readers. 